\title{
0 ensino superior em tempos de pandemia: a perspectiva dos estudantes da Universidade da Madeira
}

Andreia Micaela Nascimento ${ }^{1}$

\section{RESUMO}

Neste texto, apresentam-se os dados preliminares de uma investigação sobre o impacto do Ensino Remoto durante a pandemia. Com o objetivo de compreender as dificuldades dos estudantes e determinar quais desafios lhes trouxeram a suspensão de toda a atividade letiva presencial, o presente estudo parte dos dados resultantes de um inquérito por questionário, aplicado em parceria com a Associação Académica da Universidade da Madeira (AAUMa) e o seu Observatório da Vida Estudantil. A análise dos dados permite ensaiar um retrato dos principais desafios, dificuldades e dilemas experienciados pelos estudantes, destacando-se a preocupação com a conclusão do curso, a entrada no mercado de trabalho e, simultaneamente, os efeitos do confinamento no bem-estar e saúde mental.

Palavras-chave: Ensino Superior. Pandemia Covid-19. Ensino remoto. 
Higher education in times of pandemic: the perspective of students at the University of Madeira

\section{ABSTRACT}

This text presents preliminary data of an investigation on the impact of distance learning during the pandemic. The objective is to understand the difficulties of students and determine what challenges the suspension of all teaching activities posed to them. In person, this communication is based on data resulting from a questionnaire survey, applied in partnership with the Student's Union of the University of Madeira and its Observatório da Vida Estudantil. The analysis of the data allows rehearsing a portrait of the main challenges, difficulties, and dilemmas, highlighting the concern with the conclusion of the degree and the entry into the labor market and, simultaneously, with the effects of social confinement on welfare and mental health.

Keywords: Higher education. Pandemic Covid-19. Remote teaching. 


\section{INTRODUÇÃO}

A pandemia de Covid-19 desencadeou mudanças sem precedentes nos países, nas empresas, nas instituições e em todos os domínios da sociedade, forçando o mundo a adaptarse e a reinventar-se. Num espaço de horas, e sem aviso prévio, populações inteiras foram aprisionadas, física e emocionalmente, obrigadas a reorganizar rotinas e a ver o mundo através da janela off-line e on-line (NASCIMENTO, 2020).

Na tentativa de mitigar a propagação da Covid-19, foram fechados serviços e empresas; o trabalho passou a ser desempenhado de forma diferente, e o ensino promovido a distância por meio de diversas plataformas digitais partilhadas por pais e alunos, professores e educadores, agora especialistas em tecnologias (TAYLOR, 2018).

A Universidade da Madeira (UMa), a mais jovem e pequena instituição de Ensino Superior público portuguesa, seguindo as orientações emanadas pelas autoridades de saúde nacionais e regionais, determinou a suspensão de toda a atividade letiva presencial e a sua substituição por métodos digitais para a promoção do Ensino à distância. A escola acabou, mas a aula continuou (ZHOU et al., 2020) e foi necessário estabelecer, com caráter de urgência, um elo entre a rotina de isolamento e a continuidade do ensino. O Ensino On-line afirmou-se, assim, como uma solução viável para ultrapassar os constrangimentos impostos pela pandemia e minimizar os efeitos da ausência de interação presencial.

Apesar da existência de alguns estudos sobre o impacto da pandemia no ensino, a perspectiva dos estudantes universitários sobre a própria aprendizagem é ainda um campo pouco trabalhado, principalmente em instituições de Ensino Superior localizadas em regiões mais isoladas e periféricas. Foi com o objetivo de compreender quais as dificuldades dos estudantes, bem como determinar quais desafios a experiência de aprendizagem on-line trouxeIhes, que o presente estudo foi realizado.

Em que condições decorreram as atividades não presenciais? Quais são os principais desafios que enfrentaram? Que questões podem ser discutidas e melhoradas no futuro? Essas são algumas das perguntas que se procura dar resposta.

\section{O ENSINO SUPERIOR EM TEMPOS DA PANDEMIA}

\subsection{Instrumentos de recolha de dados e procedimentos}

A coreografia metodológica do estudo levou em conta a pluralidade de questões e perspectivas equacionadas, pelo que uma estratégia metodológica quantitativa se revelou, à partida, como a mais adequada (BRYMAN, 2012; JANESICK, 2015; QUIVY; CAMPENHOUDT, 2008).

$O$ instrumento de recolha de dados integrava questões abertas e fechadas e incluía quatro secções, para além dos dados biográficos dos estudantes: averígua-se (1) as condições logísticas e técnicas que possibilitam ou dificultam a existência do Ensino Remoto; (2) a experiência de ensino e aprendizagem nas diferentes unidades curriculares, em que se incluíam itens sobre a 
experiência de aprendizagem a distância e tipo de ensino preferencial para o ano letivo subsequente; (3) a avaliação, que integrava um conjunto de questões sobre as práticas de avaliação e; (4) o Ensino Remoto e os efeitos do confinamento no bem-estar e saúde mental.

Os dados foram recolhidos entre os dias 23 de junho e 10 de julho de 2020, junto de estudantes universitários matriculados na Universidade da Madeira, em diferentes áreas de conhecimento e ciclos de estudo, através de um inquérito por questionário telefônico.

A amostra é, então, constituída por um total de 436 estudantes, sendo 69,7\% do sexo feminino e $30,3 \%$ do sexo masculino, ou seja, predominância de mulheres entre os estudantes universitários, uma tendência já identificada em estudos anteriores (NASCIMENTO; VIEIRA, 2018; THOMAS DOTTA; LOPES; LEITE , 2019). A maioria dos estudantes inquiridos - 91\% - frequenta o primeiro ciclo de estudos.

Trata-se de uma amostra por conveniência, visto que os dados apresentados têm um valor estritamente exploratório, não devendo ser interpretados como representação da comunidade estudantil da UMa. Não obstante, a literatura existente mostra que este tipo de amostra, apesar de inadequado para a existência de extrapolações da amostra para o universo (ROSA, [s. d.]), não deixa de indicar pistas interessantes a serem exploradas em estudos futuros mais aprofundados.

\subsection{A experiência antes e durante a pandemia: dificuldades}

O discurso direto dos inquiridos sobre as dificuldades que sentiram com a crise pandêmica, "de novas experiências e necessidade de adaptação" a novas realidades social, cultural, política, econômica e educacional, aponta, com alguma frequência, para problemas econômicos:

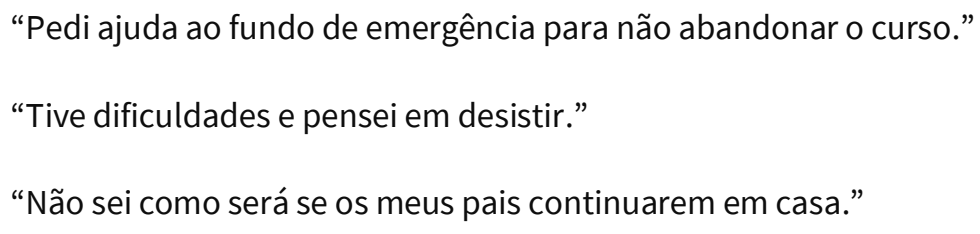

A experiência de dificuldades econômicas entre a população estudantil da UMa não é algo novo. Diversos estudos do Observatório da Vida Estudantil e dados oficiais da própria instituição apontam para um número considerável de estudantes que usufruem de apoios concedidos por meio de bolsas de estudo, fundos de emergência internos da instituição e ajudas complementares. Contudo, no contexto de pandemia, e quando questionados sobre quais as maiores dificuldades que enfrentaram, os inquiridos apontam para outro tipo de dificuldades.

Tal pode justificar-se pelo aumento do número de bolsas atribuídas pelos Serviços de Ação Social e pela Académica da Madeira, bem como pelo fato do valor da mensalidade ter baixado em quase 200 euros: de €871,52 em 2019/2020 para €697,00 em 2020/2021. Além disso, quando questionados sobre o valor médio mensal gasto na frequência do Ensino Superior durante a pandemia, a maioria dos estudantes afirma ter sido claramente inferior. A exemplo da mensalidade da propina, foram reduzidos os gastos com o alojamento, a alimentação, o material escolar e o passe, critérios que em estudos anteriores eram indicados como sendo os mais expressivos. 
Apesar de muitas famílias terem sido penalizadas financeiramente pela pandemia, o confinamento eliminou algumas das despesas fixas, com a exceção daqueles que foram obrigados a garantir recursos de informática para a realização do ensino e aprendizagem a distância.

Uma esmagadora maioria dos participantes - $94 \%$ - diz possuir computador próprio, acesso à internet em casa e condições adequadas para o Ensino à distância; no entanto, quase metade dos que afirmaram - 40\% - admitem que essas condições eram partilhadas por vários membros da família para cumprir o Ensino à distância ou o teletrabalho.

\footnotetext{
"Mais difícil do que me adaptar ao Ensino à distância é ter no mesmo espaço duas ou três pessoas a terem ou a darem aulas ao mesmo tempo. Era uma confusão."

"Os meus pais são ambos professores e ficou difícil eu ter as minhas aulas e a minha irmã as dela."

"Emprestar o meu computador à minha irmã para ela ter as aulas e termos horários em alguns tempos sobrepostos, foi uma aventura entre tantas."
}

\subsection{O ensino durante o confinamento: desafios e dilemas}

A criação da UMa, a 13 de setembro de 1988, permitiu o acesso ao Ensino Superior de vários milhares de madeirenses, com reflexos inquestionáveis ao nível da escolaridade da sua população, gerando uma mobilidade social como só a educação superior pode proporcionar, quadros para a função pública e para as empresas e o aumento de rendimentos dos jovens detentores de um diploma do Ensino Superior.

Mesmo sendo o diploma escolar um importante "atributo de inserção profissional [e] é, em larga medida através da escolarização que um projeto pessoal/profissional futuro é atualmente concebido" (VIEIRA; ALMEIDA; ALVES, 2013, p. 61), em plena crise pandêmica as preocupações associam-se, também, à necessidade que o Coronavírus trouxe de adiar ou interromper os projetos de estudo.

Quando questionados sobre a sua experiência de Ensino à distância face ao encerramento da instituição de Ensino Superior, as opiniões dividem-se: para 40,1\% foi algo positivo, e 40,9\% indicaram ter sido negativo. A ideia de que o Ensino à distância é "um mal menor face à possibilidade do cancelamento de estágios e interrupção do próprio curso e o maior dilema quando pensamos naquilo que estamos a viver" é uma constante quando os convidamos a justificar as suas respostas.

Se por um lado sobressaem aspetos ligados às características pessoais - dificuldade de concentração e de gestão do tempo - e a sentimentos e emoções - ansiedade, medo, incerteza, desmotivação -, por outro, as justificações tendem a recair essencialmente sobre a redução da qualidade dos recursos - aulas monótonas, cancelamento de estágios curriculares, falta de comunicação entre professores -, a falta de apoio e sensibilidade dos docentes - excesso de momentos de avaliação e sobrecarga de trabalho -, a falta de sociabilização com os colegas, a 
mudança repentina de hábitos e as questões de saúde e bem-estar - muitas horas em frente a um computador.

\footnotetext{
"Os docentes exageram na quantidade de trabalhos exigidos."

"A dificuldade gerada pelos professores nos exames, pois aumentaram e muito o número de exercícios deveria ser revisto."

"Houve docentes que não se adaptaram ao ensino à distância, nem souberam avaliar mediante os novos procedimentos."

"Os docentes não deviam ter sobrecarregado os alunos com tantos trabalhos."

"Os docentes deveriam ter comunicado mais entre si de forma a não sobrecarregar tanto os alunos com trabalhos, pois aumentaram imenso e as aulas continuaram a ser as mesmas que anteriormente."
}

Ainda que haja uma preocupação relativamente à situação financeira presente na voz dos inquiridos é, no entanto, possível perceber a existência de duas outras grandes questões de robustez inegável: a saúde mental dos próprios e as transformações no ensino, que colocam em causa o sucesso acadêmico e a conclusão do Ensino Superior.

Não obstante as dificuldades e os anseios, a Universidade da Madeira conseguiu cumprir as recomendações da Direção-Geral da Saúde, e isso deu segurança a quem teve, a dada altura, que se deslocar ao edifício, quer para exames quer para trabalhos laboratoriais. Não apenas, mas também por essa razão, a quase totalidade dos inquiridos - 95\% - revelou uma enorme vontade de voltar "ao normal" e à universidade, ainda que a metade deles não voltaria enquanto a pandemia estiver ativa no país.

\section{CONSIDERAÇÕES FINAIS}

Estando localizada numa região insular e com o estatuto de ultraperificidade, particularmente vulnerável às dinâmicas demográficas e às conjunturas socioeconômicas, a Universidade da Madeira enfrenta dificuldades na captação de estudantes e de recursos humanos qualificados, na angariação de financiamento para a investigação e para a ciência e na interação com o mundo econômico, social e cultural locais.

O Ensino à distância revelou-se, sem dúvida, como um novo desafio para a instituição, para os seus docentes e discentes. Contudo, e apesar das dificuldades que a pandemia impôs, a janela virtual que abriu poderá vir a contribuir para minimizar os efeitos da insularidade, luta há muito declarada pelos responsáveis institucionais.

Globalmente, embora tenham sido identificados aspectos positivos, as opiniões dos estudantes inquiridos apontam para uma visão mais negativa do que positiva. Numa avaliação global da experiência da suspensão de toda a atividade letiva presencial, e de forma independente de referirem ter sido uma boa ou má adaptação ao novo sistema de ensino, é possivel identificar alguns motivos: as competências sociais e emocionais dos estudantes, bem 
como a qualidade e celeridade da resposta institucional à transição do Ensino presencial para o Ensino à distância.

Num final de ano letivo atípico, com Ensino à distância, famílias em quarentena, serviços encerrados abrangidos pelo regime de lay off ou em teletrabalho, desemprego, incertezas e angústias diversas, o presente estudo, exploratório e preliminar, mostrou ser fundamental que se trabalhe, em profundidade, os temas evidenciados.

\section{REFERÊNCIAS}

BRYMAN, A. Social Research Methods. 4. ed. Oxford: University Press, 2012.

JANESICK, V. J. Stretching: exercises for qualitative researchers. California: Sage Publications, 2015.

NASCIMENTO, A. M. Da pré à pós pandemia: Desafios e dilemas da investigação. Lisboa: Life Research Group Blog, 4 de nov. 2020. Disponível em: https://liferesearchgroup.wordpress.com/2020/11/04. Acesso em: 4 dez. 2021.

NASCIMENTO, A. M.; VIEIRA, M. M. Research Brief 2018: Os caloiros da Universidade da Madeira: retratos e alguns desafios. Lisboa: Observatório Permanente da Juventude/Instituto de Ciências Sociais da Universidade de Lisboa, 2018.

ROSA, L. V. Sebenta da cadeira de Métodos e Técnicas de Investigação Sociológica do $3 .^{\circ}$ ano da Licenciatura em Sociologia. Lisboa: Faculdade de Ciências Sociais e Humanas/Universidade Nova de Lisboa, [s. d.].

TAYLOR, Z. W. Web accessibility: Not just for tech experts anymore. Disability Compliance for Higher Education, v. 23, n. 9, p. 1-16, 2018.

THOMAS DOTTA, L.; LOPES, A.; LEITE, C. O movimento do acesso ao ensino superior em Portugal de 1960 a 2017: Uma análise ecológica. Arquivos Analíticos de Políticas Educativas, v. 27, n. 146, 2019. Disponível em: https://doi.org/10.14507/epaa.27.4195. Acesso em: 4 dez. 2021.

VIEIRA, M. M.; ALMEIDA, A. N.; ALVES, N. Ponto de chegada ou (novo) ponto de partida? Entrada na Universidade, experiência estudantil e dilemas da individuação. In: ALMEIDA, A. N. (coord.). Sucesso, Insucesso e Abandono na Universidade de Lisboa: Cenários e Percursos. Lisboa: Educa, 2013.

ZHOU, L. et al. 'School's out, but class 'on'. The largest online education in the world today: taking China's practical exploration during the Covid-19 epidemic prevention and control as an exemple. Best Evidence of Chinese Education, v. 4, n. 2, p. 501-519, 2020. 